\title{
Efficacy of an Emotional and Cognitive Regulation Programme for Mathematics Problems Solving
}

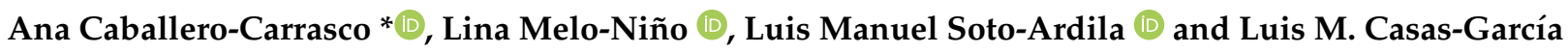 \\ Facultad de Educación, Universidad de Extremadura, 06006 Badajoz, Spain; lvmelo@unex.es (L.M.-N.); \\ luismanuel@unex.es (L.M.S.-A.); luisma@unex.es (L.M.C.-G.) \\ * Correspondence: acabcar@unex.es
}

check for

updates

Citation: Caballero-Carrasco, A.; Melo-Niño, L.; Soto-Ardila, L.M.; Casas-García, L.M. Efficacy of an Emotional and Cognitive Regulation Programme for Mathematics Problems Solving. Sustainability 2021, 13, 11795. https://doi.org/10.3390/ su132111795

Academic Editors: David Molero and Inmaculada García-Martínez

Received: 24 September 2021

Accepted: 18 October 2021

Published: 26 October 2021

Publisher's Note: MDPI stays neutral with regard to jurisdictional claims in published maps and institutional affiliations.

Copyright: (c) 2021 by the authors. Licensee MDPI, Basel, Switzerland. This article is an open access article distributed under the terms and conditions of the Creative Commons Attribution (CC BY) license (https:/ / creativecommons.org/licenses/by/ $4.0 /)$.

\begin{abstract}
The purpose of this study was to analyse the efficacy of an emotional and cognitive regulation programme in mathematics problem solving (MPS) in primary education preservice teachers (PEPSTs). The objective was that the PEPSTs learn to solve mathematical problems and become aware of their emotions, self-regulating their learning process. The programme consists of two parts: the first one involves awareness and control of one's affective responses before the MPS, and the second one involves an integrated model of MPS and emotional control (IMMPS). For the study, we opted for a pre-experimental pretest/posttest design with an experimental group and the complementarity of qualitative and quantitative methods. Some of the results that were obtained were greater emotional control in the PEPSTs, reducing the anxiety and blockages that MPS initially caused them.
\end{abstract}

Keywords: problem solving; emotional development; anxiety; preservice teacher education; mathematics education

\section{Introduction}

Mathematics problems solving (MPS) has been considered for decades as the centre of mathematics teaching, as it demonstrates the ability to analyse, understand, reason and apply. At the same time, it is also considered to be specific content when highlighting it as a basic competence that students should acquire.

Thus, as indicated by [1], different school curricula have established developing and evaluating aspects related to:

(1) The development of the problem: the understanding and analysis of the statement, the design and application of resolution strategies, the verification habits and their coherence within the context presented.

(2) Communicating problem-solving processes and results: the relationship between language and problem solving is specified at different stages around the world in relation to general problem-solving models.

(3) The affective domain and emotional education when assessing personal attitudes, such as perseverance in the search for solutions, confidence in one's ability to achieve them or a positive attitude when it comes to contrasting solutions relative to their peers.

However, these considerations have not been clearly reflected in teaching practice [2]. Thus, students of different educational levels consider MPS as being mechanical and memoristic, they have scarce resources to represent and analyse problems, they do not search for different strategies or methods for their resolution or make use of the different indications made by the teacher [3-10]. Primary education students have internalized that all problems have a single solution that is reached by implementing arithmetic operations using all the data included in the statement. This leads them to develop an automated approach to a known problem format that students follow to reach the solution in a straightforward manner [11]. They also do not perform metacognitive processes, such as generalization 
and regulation, as well as other processes, such as control and reading [11]. Likewise, in textbooks, the attention to learning heuristic strategies for problem solving $[12,13]$ is conspicuous by its absence.

Regarding communication, students have difficulty verbally explaining the resolution strategy to be developed.

Regarding the affective domain, there have been multiple studies in recent years that have described and analysed the role of affective variables (i.e., beliefs, attitudes, emotions and anxiety) in mathematics and, more specifically, in MPS. It was found that primary education preservice teachers (PEPSTs) usually have a medium level of anxiety towards mathematics $[14,15]$.

According to Hill et al. [16], math anxiety is a negative emotional response of learners to their current or prospective situation involving mathematics. This happens in an educational process when mathematics teachers introduce new topics with insufficient use of suitable models and a low stage of visualization, and when they present new mathematical notions, such as "ready mathematics", without steps that show how the new notions were created [17].

Despite the considerable number of research articles on the subject [18] and the proven effectiveness of emotional education in the social, emotional and total self-concept [19], as well as in mathematics learning and problem solving [20], there are no concrete proposals in this regard in mathematics education and, more specifically, in MPS.

Preservice teachers (PEPSTs) expect to be "taught to teach" in mathematics teaching subjects and to be shown "resources to teach mathematics classes" [21], with these expectations being related to their future needs as teachers. Therefore, it is obvious that it is necessary to introduce activities in teacher training curricula so that they can not only extend their knowledge of the mathematical content but also include MPS as content and the affective variables involved in it.

Significant relationships were found between some of the variables related to emotional intelligence and mathematical performance [22,23]. Other research showed the influence of teachers' affections on those of students and their achievements [24,25].

Considering this situation and the lack of work that has been aimed at intervention in this regard, an emotional and cognitive regulation programme regarding MPS was designed.

The general objective of this programme is to provide future teachers with a didactic tool that allows them to learn and to "learn to teach" in order to manage emotions and self-regulate their learning process in MPS.

To do this, the present article aimed to provide PEPSTs with heuristic strategies and techniques for solving mathematical problems; enhancing the search for different "paths" for MPS; and becoming aware of their own conceptions, attitudes and emotions so that they reflect on these variables. By training in techniques for managing behavioural responses towards MPS, they can control and/or modify them.

In this way, the programme intends to develop competences that are related to awareness, regulation and emotional autonomy.

The backbone of the programme is the integrated model of MPS and emotional control (IMMPS, Figure 1), which was developed by mathematics authors [26,27] based on emotional education models $[20,28,29]$.

In this way, it combines the heuristics that are used in the different phases of MPS with physiological response management techniques (Jacobson's breathing and muscle relaxation technique) [30] and cognitive techniques (self-instructions) [31].

The IMMPS concludes with a fifth phase that involves personal reflection about (1) the process followed to solve the problem, (2) attitudes and emotions and (3) personal progress, as well as the proposal of small goals for the next mathematical problem to be solved. So far, these aspects have not been considered in other MPS models. 
HEURISTICS
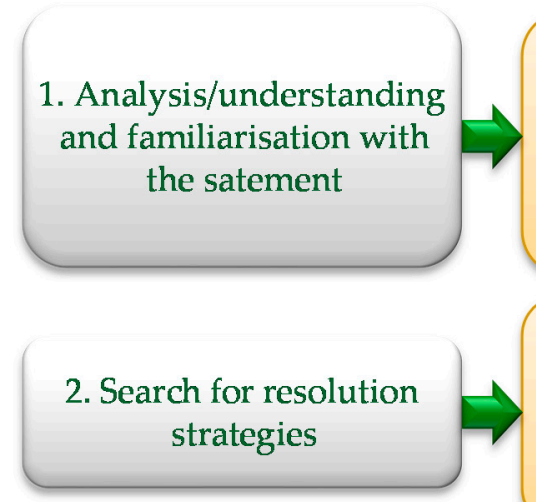
conditions...
Reread the statement, notations, graphic, extraction of explicit and implicit data and objectives, determine contexts and

Relate unknown data, previous knowledge, restate the problem, state sub-problems...

Breathing

Muscle relaxation

Self-instructions

Record and explain all the steps, act with rigour, order and precision...

\section{EMOTIONAL CONTROL}

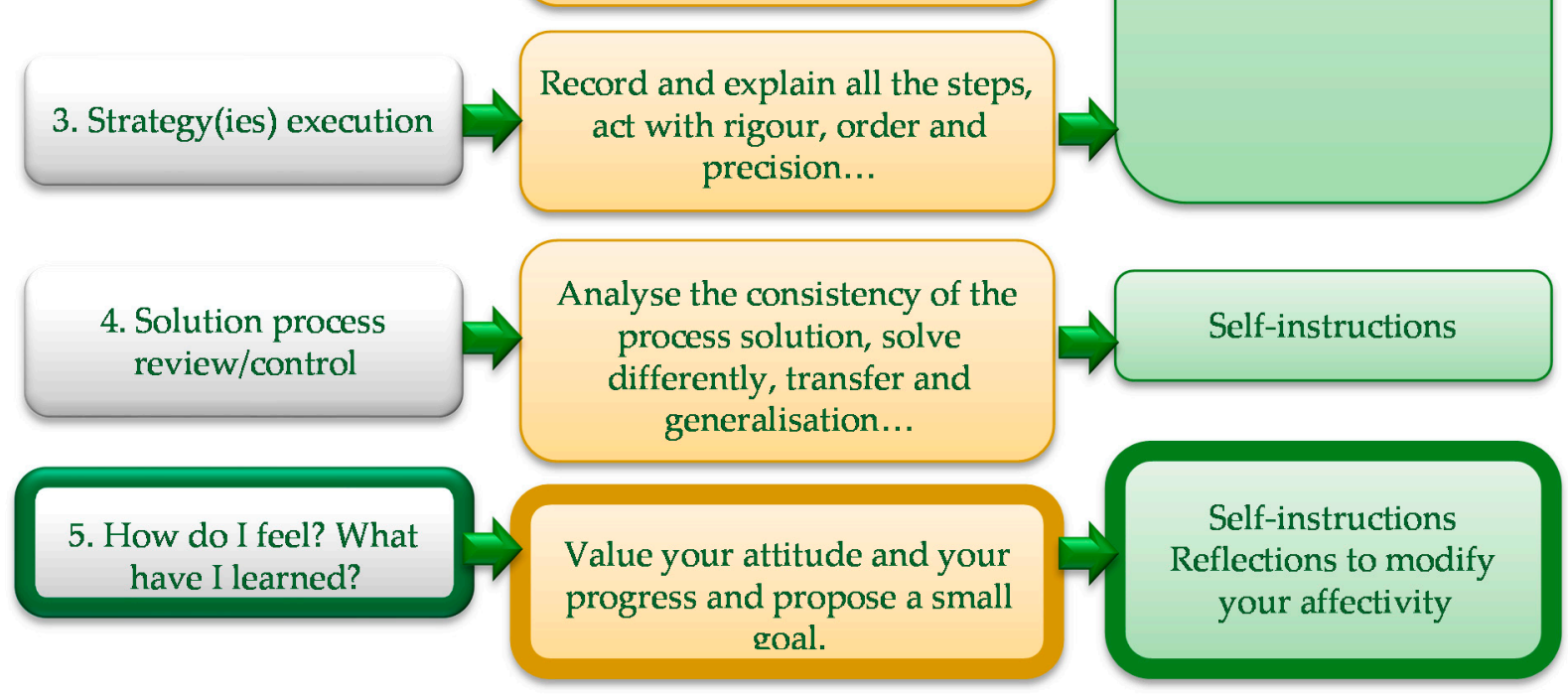

Figure 1. Scheme of the integrated model of MPS and emotional control (IMMPS).

\section{Method}

\subsection{Participants}

The sample, which resulted from an incidental non-probabilistic sampling, was composed of 60 PEPSTs in their third year attending the Mathematics Didactics II course. Of these, $14(23.33 \%)$ were men and $46(76.67 \%)$ were women. The vast majority of students, 55 were under 25 years of age, 4 were between 25 and 30, and 1 was over 30 .

\subsection{Instruments}

For the collection of data, the complementarity of quantitative and qualitative methods was chosen, using the following instruments.

\subsubsection{State-Trait Anxiety Inventory for Adults (STAI) Adapted to MPS}

The subscale STAI A/E of the Spanish version of STAI [32] was chosen. Existing mathematical anxiety scales have not been used with PEPSTs. Other scales consider anxiety as an attitude (not corresponding to the theoretical framework adopted in this research, where we consider anxiety as an emotional state) or measure mathematical anxiety in general, without paying any specific attention to MPS.

The STAI A/E subscale describes how people feel at a particular time. Thus, it can be applied to determine the levels of anxiety by applying experimental procedures involving induced tension or stress (MPS in this case). The A/E score shows the level of transient anxiety of a group that is subjected to behaviour modification. This means that this score can be used to measure the changes that occur in the A/E variable in similar situations, which is 
a possibility that we exploited in this work in order to evaluate an emotional and cognitive regulation programme in mathematics problem solving. According to the test manual of the instrument, the A/E subscale can be altered to assess the level of intensity "state" in a given situation for a specific time interval of interest to a researcher. Thus, to focus on the reactions of PEPSTs towards MPS, the phrases "when I am solving mathematical problems", "when I face a mathematical problem", "when solving a mathematical problem" or "before a mathematical problem" were added to the original sentences, as appropriate.

The scale includes 20 items -10 using a direct qualification and 10 using an inverted one-with a four-point response scale, ranging from nothing (0) to a lot (3). The total score could thus vary between a minimum of 0 and a maximum of 60 . The instrument shows a high degree of reliability and validity (with a high Cronbach's alpha value of 0.92 for the Spanish version).

This scale was administered at the beginning of the programme (pretest), at the end of the programme (posttest) and four months after the last session (retest).

2.2.2. Questionnaire: "What you think, feel and do, before, during and after MPS activities."

This was a questionnaire that was designed to analyse the behavioural responses towards MPS, together with the impressions evoked by the subjects (PEPSTs) at the different MPS stages: before engaging with the problem, while it was being solved and after having faced it.

It consisted of 3 questions in relation to what the PEPSTs thought (cognitive level), felt (emotional level) and did (motor level) when faced with MPS, which were administered in the three different moments of MPS referred to above. This process was carried out at the beginning of the programme (pretest) and at the end of the program (posttest).

The categories of responses were the cognitive, emotional and motor levels regarding MPS. Each of these categories contained two subcategories, namely, positive and negative.

(1) Cognitive level-This answered the questions: what do I think, what do I imagine, what do I believe, what ideas do I have and what do I say to myself? This corresponded to aspects related to our beliefs, ideas, mental representations, thoughts, schemes, attributions, expectations, etc. An alteration at the cognitive level interferes with our behavior in general and our performance in particular since it affects basic mental processes, such as perception, attention and concentration. Asking ourselves what we think and what we say to ourselves during MPS activities is a way to identify the manifestation of this level. If our internal dialogue is positive, i.e., if it is aimed at achieving our goal and the objectives that we set ourselves, it facilitates and determines the result and, in addition, it denotes confidence and security. If we tell ourselves that we are going to try to achieve our goals and that we have the resources to do so, success is not guaranteed but it will be easier to attain. If, on the other hand, our "internal dialogue" is negative and is not aimed at solving the situation ("I won't be able", "I won't succeed", "I have neither the strength nor ability", etc.), the failure many people experience in MPS will be thus accounted for. Ultimately, self-talk also explains our behaviour and the results we obtain, both successes and failures. Hence, the inclusion of self-instructions in the integrated model is used to incorporate a technique that is widely used to handle internal self-talk, expectations and thoughts.

(2) Emotional level-This answered the question: how do I feel? This level included the emotional responses that were triggered when evaluating MPS activities. These responses could be positive or negative, for example, insecurity, frustration, hope, optimism, fear, joy, anger and sadness. The program under study aimed to positively modulate these responses with exercises, relaxation and by consciously modifying the meaning given to MPS, positively reevaluating thoughts and beliefs linked to this task through self-instruction.

(3) Motor level-This answered the question: what do I do? This behavioral level referred to the way we act in MPS, what we do, the relationships we establish with others, etc. 
It is the most visible sphere of behavior and it manifests itself externally; giving up on the activity, trying to solve the problem, extracting data, rereading the problem, waiting for a colleague to solve the problem, etc., would be indicators of this level. Habits are beneficial for managing this level. In the program under study, it was proposed to use the integrated model of MPS as a habit to train for MPS.

\subsection{Procedure}

This was an evaluative investigation with a quasi-experimental methodological design with a pretest and posttest, which involved assessing the levels of anxiety of the students and their cognitive, emotional and motor responses after the application of the emotional and cognitive regulation programme in MPS.

The complete investigation was carried out in three cyclic phases in two consecutive years: reality analysis, programme development and evaluation of results. In this way, the evaluation of the first year (pilot experience) served to redesign the programme and develop this cyclical process with the final programme presented here. The three cyclical phases are described below.

(1) Analysis of reality and planning:

- Study of the reality under study.

- Definition of the purpose and objectives of the programme.

- Planning and sequencing actions.

- Identification of the intervening subjects.

- Programme evaluability study.

(2) Programme and research plan development:

- Operational definition of the variables.

- Selection of techniques and instruments for collecting information and data.

- Collection of information and data.

- Data analysis.

(3) Evaluation of results and decision making:

- Analysis of the results regarding the objectives.

- Judgment formulation.

- Report writing.

- Decision making.

\subsection{Emotional and Cognitive Regulation Programme in MPS}

The general objective of the programme was to provide future teachers with a didactic tool that would allow them to learn and to "learn to teach" to solve math problems, taking into account cognitive aspects and emotional education aspects.

The specific objectives that were aimed at were the following:

- To reflect on the attitudes, beliefs and emotions of the participants in relation to MPS.

- To show and train an integrated model of MPS that integrates cognitive skills related to MPS.

- To train the use of tools for emotional regulation, specifically anxiety, that originate in MPS processes.

- To raise awareness about wrong and unfavourable beliefs about MPS and about themselves as learners and problem solvers.

- To develop positive attitudes towards MPS.

- To promote and optimise emotional control towards MPS and reduce the level of anxiety that PEPSTs may experience in this mathematical activity.

In the programme (developed in 13 sessions of two hours each), two distinct parts can be distinguished. 
The first part was focused on raising awareness and reflecting on one's conceptions, attitudes, emotions, levels of anxiety, beliefs and generalised expectations of control by the PEPSTs themselves, and on how these aspects influence students' performance.

Likewise, in this first part, students were instructed in the different techniques for their control and/or modification, as explained above.

In the second part of the programme, the IMMPS is instructed and experienced from the students' reflections, which integrated both heuristics for the MPS and emotional control techniques. For this, the following activities were carried out:

1st Session: Presentation of the programme.

Presentation and justification of the programme, evaluation of self-perception as problem solvers, evaluation of knowledge and conceptions about MPS and evaluation of affection towards MPS.

2nd Session: Conceptions and affections on MPS.

Presentation and discussion of the results of the previous session so that the PEPSTs become aware of their own and common conceptions, beliefs, attitudes and emotions towards MPS. This was about promoting the need to modify different conceptions and affects. In addition, two fora were opened in the Moodle virtual platform: "The affective domain and the MPS" and "The traditional conception about MPS". We used the fora (asynchronous communication) to make it possible to discuss certain contents and the common questions regarding their doubts and difficulties. This facilitated students' reflection on their own process of learning by gaining awareness from their own difficulties and those of others. This would mainly consist of multidirectional interactions in which ideas and arguments with respect to a proposed subject were interchanged. The PEPSTs, when they see their difficulties reflected in others, do not feel alone in the learning process, which enhances their motivation and arouses their interest in their progress. People who share a problem will be more willing to talk to each other about the same problem.

3rd Session: Problem and exercise.

Through examples of diverse mathematical activities, the distinctions between exercise and problem, and therefore between productive and reproductive thinking, and between techniques, strategy learning and learning strategies were reinforced. A Moodle forum, entitled "Exercise and Problem" was thus proposed.

4th Session: Personal involvement in MPS (I).

Evaluation of anxiety towards MPS and of affection and reactions at the different times during MPS.

In this session the pretest of the questionnaire: "What you think, feel and do, before, during and after MPS" and the State-Trait Anxiety Inventory for Adults (STAI) pretest adapted to MPS were applied.

The PEPSTs were expected to appreciate the impressions and emotions (cognitive and emotional level) that arose before the MPS and how these affects influenced how they acted (motor level).

5th Session: Personal involvement in MPS (II).

Behaviour and behavioural levels (cognitive, physiological, emotional and motor), levels of stress and anxiety and their manifestations and their relation to performance were explained.

6th Session: Emotional development strategies.

A presentation and discussion of the results of the previous questionnaire were carried out, together with an analysis of the interventions in the forum. This made PEPSTs aware of the physiological, cognitive, emotional and motor responses that arose before MPS. Next, we implemented training modification techniques and behavioural training: breathing and muscle relaxation [30] for a correct management of physiological responses to MPS 
and elaboration of personalised self-instructions [31] to manage cognitive and emotional responses to MPS.

Self-instruction consisted of modifying and replacing negative self-dialogues with positive ones. In the first phase of the IMMPS, the self-instructions focused on using emotions as a signal to implement the emotional control techniques and guiding the problem solver through positive comments by preparing them to face the problem (examples: "I already solved this successfully on another occasion", "there is no reason to worry"). In the second and third phases, strategies to search for solutions and the execution of strategies were presented, respectively, and the self-instructions focused on facing the situation and guiding the process (examples: "I can do it, in fact I am doing it", "If I make mistakes, it's normal, I can correct them").

In the fourth phase, which involved review/control of the solution process, selfinstructions were addressed to the solver, where they praised themself for having faced the situation ("I understood or at least I tried", "I have given myself the opportunity to learn and that's what matters").

In the fifth phase, the PEPSTs engaged in appreciating the attitudes, emotions and efforts that were developed during the resolution of the problem. They reflected on the personal progress achieved. The PEPSTs determined whether their attitudes had improved, whether they had handled cognitive-emotional responses, whether they had increased their expectations of success and self-efficacy, etc. Based on this analysis, they set a goal for the following problem.

7th Session: IMMPS heuristics.

In what follows, we propose some heuristics that can be used in each of the different phases to be implemented in this session.

In the first phase of the IMMPS, which involved the analysis, understanding and familiarisation with the statement (of the problem), some heuristics to be used are reread the statement and mentally imagine the situation; express the statement in other terms or formulate it in other words; produce notation; use graphs and diagrams; select the appropriate material or have a manipulative model; determine the available data (explicit and implicit) and problem conditions; break down the problem into smaller segments; and, if possible, analyse the context and explicit and implicit concepts and processes, exemplify special cases and define the objective of the problem.

In the second phase of the IMMPS, search for resolution strategies. Here, some heuristics are remember and explore similar problems in form, data or conclusions or with fewer variables; find the relationship between the data and the unknown and with the conditions of the problem; simplify (discarding cases, eliminating conditions by imposing conditions on variables); estimate and guess; decompose the problem and state subproblems; starting from particular cases; argue for a contradiction; assume the result and work from it; and relate it to the initial conditions.

In the third phase of the IMMPS, i.e., strategy(ies) execution, some heuristics are record and explain all the steps; highlight intermediate achievements; act with rigour, order and precision; and control the status of execution.

In the fourth phase of the IMMPS, i.e., process solution review/control, some heuristics are review the statement and the objective of the problem, review the process, review the concepts involved and review the solution obtained and its coherence.

In the fifth phase, the suggestions are to assess the attitude towards the problem, meditate on the effort made, determine the progress made in solving this problem relative to others, and indicate a small goal to achieve for the next problem.

8th Session: IMMPS development with example problems.

Two activities that were not really a problem for the solver were conducted. IMMPS was not essential for their resolution, but a third one, which was a real problem, was solved by applying IMMPS. The difference in the procedures for the resolution of the first two activities and the third one became evident: the resolution of the first two involved a 
mere application of algorithms and formulae, but to solve the third one, heuristics were necessary. It comprised the implementation of some training in the different techniques that were used for managing emotional, physiological and cognitive responses, as well as heuristics to internalise the IMMPS.

9th Session: IMMPS development with a specific problem.

Application of the IMMPS in a problem for its internalisation and automation: manage physiological, cognitive and emotional responses that may arise towards the MPS; learn how to define a mathematical problem by capturing its objectives, by developing the ability to describe it and identifying the most relevant information; design, describe and select the possible strategies that lead to the solution of the different mathematical problems that might arise; execute the selected strategy for solving the mathematical problem, while ensuring that the process is orderly and rigorous and controlled at all times; and reflect on the adequacy of the answer given to the given mathematical problem and on the process followed throughout its resolution.

10th Session: IMMPS development with a concrete problem.

Application of the IMMPS to a problem to achieve its internalisation and automation. Learning is possible only through practice and experience; thus, to improve problemsolving skills, many problems need to be solved [17].

11th Session: IMMPS activities with elementary students.

In this phase, we worked on specific activities on IMMPS that were to be developed with primary school students; PEPSTs practiced the different stages of IMMPS, working mainly on the understanding and analysis of the problem and the design of strategies. For this, we posed problems in which data were missing, which led to errors, where the answer was given in the statement and whose objective was to elaborate a statement based on data, an algorithm or a specific situation. These were problems that highlighted the need to understand and analyse the statements.

12th Session: IMMPS autonomous application.

Autonomous resolution of a problem by applying the IMMPS to achieve its internalisation. 13th Session: Evaluation of anxiety, affection and reactions at the different times of MPS.

In this session, the posttest of the questionnaire "What you think, feel and do, before, during and after the MPS activity" was applied, as well as the adapted posttest of the State-Trait Anxiety Inventory for Adults (STAI).

Four months later, a retest session was conducted using this latest inventory.

Throughout the development of the programme, the Moodle virtual platform (Modular Object-Oriented Dynamic Learning Environment) was used. Through Moodle, the PEPSTs participated in forums and wrote a diary after each session, which enhanced their reflection and made it possible to follow their evolution and feedback regarding both cognitive and affective aspects. This participation facilitated the collection of information for its subsequent analysis.

The mathematical problems that were worked on were varied and presented a certain degree of difficulty for them; they should not be too difficult to encourage them to persevere, but that they should be complex enough to encourage reflection on the resolution process they have experienced. Thus, assuming the indications made by Santos [10], regarding the problems posed in his research, the mathematical problems that were used were designed to be accessible to students, given their previous knowledge. They could be solved in different ways or following new paths. They illustrated important mathematical ideas, did not involve tricks or solutions without explanation and allowed for extension or generalisation to other contexts. Teachers need to select problems with different difficulty levels and gradually propose them to the PEPSTs until their problem-solving skills are sharpened [17].

At all times, we considered the need to experiment and reflect on the experience as the basis for acquiring new knowledge. 


\section{Results}

The results on the effectiveness of the programme are described below.

Regarding the variable anxiety towards MPS, the pretest results revealed that the PEPSTs did not feel calm, comfortable, happy or relaxed before the MPS. Instead, they felt somewhat altered, distressed, restless and tired and, to a lesser extent, oppressed, stunned and overexcited. Before the MPS activity(ies), they also showed concern to an even greater degree. Something similar happened with the possibility of failure, which was found along with other feelings, such as insecurity, tension, contrariety and a lack of satisfaction and self-confidence before the RPM.

On the other hand, in the posttest, i.e., after the programme was applied, the results showed that PEPSTs were calmer, more comfortable, more rested and more relaxed than before the MPS activity and did not experience oppression, attention and overexcitement. In addition, they presented more security and satisfaction and, to a greater degree, selfconfidence than before the MPS activity. At the same time, they did not experience, or did so to a small extent, the following feelings: concern about the MPS activity and possible failure in the task, nerves, tension, alteration, restlessness, anguish and disappointment; meanwhile, they did experience joy. Thus, as shown in Table 1, where the pretest and posttest scores are compared, we noticed a decrease in the means of the values referring to these feelings.

Table 1. Intragroup comparisons of the anxiety-state variable in MPS in the pretest, posttest and retest phases.

\begin{tabular}{|c|c|c|c|c|c|}
\hline & & $M$ & $D T$ & $t$ & Sig. (Bilateral) \\
\hline \multirow{2}{*}{ Pretest-Posttest } & Pretest & 32.41 & 10.66 & \multirow{2}{*}{3.486} & \multirow{2}{*}{$0.002 * *$} \\
\hline & Posttest & 24.70 & 12.78 & & \\
\hline \multirow{2}{*}{ Pretest-Retest } & Pretest & 32.41 & 10.66 & \multirow{2}{*}{2.190} & \multirow{2}{*}{$0.038 *$} \\
\hline & Retest & 27.93 & 11.86 & & \\
\hline \multirow{2}{*}{ Posttest-Retest } & Posttest & 24.70 & 12.78 & \multirow{2}{*}{-1.224} & \multirow{2}{*}{0.232} \\
\hline & Retest & 27.93 & 11.86 & & \\
\hline
\end{tabular}

In the retest (four months after the end of the intervention programme), the PEPSTs felt somewhat calmer, more rested, more self-confident, happier and better disposed when confronted with MPS activities, and did not experience distress. In addition, they presented some comfort, safety, relaxation and satisfaction. Along with this, they experienced tension, some nerves, restlessness and disappointment. As for the possible failure before the MPS activity, half of the PEPSTs said that they were either "not worried" or "somewhat worried", in contrast with the other half, who chose "enough" or "much". At the same time, the following factors did not show, or did so to a small extent: concern about the MPS activity, alteration, oppression, stunned and overexcitement. Hence, there was a slight increase in anxiety relative to the posttest, while still maintaining a considerable decrease in the above-mentioned state of anxiety before the MPS in relation to the pretest (see also Table 1).

Once the assumptions of normality, homogeneity of variance and randomisation were satisfied, a parametric test, namely, Student's $t$-test, for related samples was carried out to analyse the mean differences between the pre-test and the posttest, between the pretest and the retest and, finally, between the posttest and the retest.

This analysis showed statistically significant differences in the averages between the pretest and the posttest $(t=3.486$, sig. $=0.002, p<0.01)$ and between the pretest and the retest $(t=2.190$, sig. $=0.038, p<0.05)$, while the comparison between posttest and restest did not show statistically significant differences $(t=-1.224$, sig. $=0.232, p>0.05)$. Table 1 below shows the complete data. 
It was therefore evident that the PEPSTs showed a lower level of anxiety towards MPS activities after the intervention, a situation that persisted four months afterwards since the average obtained at this time, despite being slightly higher than the corresponding one at the end of the programme, did not show significant differences with it but with the one found prior to the intervention.

This slight decline months after the programme, although not significant, was understood as a normal consequence of the passage of time. However, in this last phase, greater confidence, calm, well-being and joy towards MPS were perceived; while a practical disappearance of anguish was perceived and levels of comfort, safety, restlessness and alteration were maintained relative to the posttest. In contrast, although to a small extent, there was an increase in insecurity, nerves, tension, contrariety, concern about possible failure, concern about MPS, oppression, being dazed and overexcitement, as well as a decrease in the feeling of comfort, rest and relaxation.

Table 2 shows the results obtained at different times for the questionnaire "What you think, feel and do, before, during and after the MPS".

Table 2. Results of the questionnaire "What you think, what you feel and do ... " at different times.

\begin{tabular}{|c|c|c|c|c|c|c|c|c|c|}
\hline & & \multicolumn{2}{|c|}{ Before MPS } & \multicolumn{2}{|c|}{ During MPS } & \multicolumn{2}{|c|}{ After MPS } & \multicolumn{2}{|c|}{ Total } \\
\hline & & Pretest & Posttest & Pretest & Posttest & Pretest & Posttest & Pretest & Posttest \\
\hline \multirow{2}{*}{$\begin{array}{c}\text { Cognitive } \\
\text { level }\end{array}$} & Positive self-dialogues & 24 & 43 & 17 & 36 & 16 & 39 & 57 & 118 \\
\hline & Negative self-dialogues & 31 & 5 & 32 & 8 & 33 & 9 & 96 & 22 \\
\hline \multirow{2}{*}{$\begin{array}{c}\text { Emotional } \\
\text { level }\end{array}$} & Positive emotions & 12 & 23 & 9 & 28 & 21 & 36 & 42 & 87 \\
\hline & Negative emotions & 41 & 25 & 43 & 19 & 30 & 14 & 114 & 58 \\
\hline \multirow{2}{*}{ Motor level } & Positive performances & 36 & 44 & 35 & 42 & 16 & 19 & 87 & 105 \\
\hline & Negative performances & 19 & 0 & 20 & 0 & 12 & 1 & 51 & 1 \\
\hline
\end{tabular}

Observation of the data showed us that the number of positive responses was lower in the pretest in all cases compared to a greater number of this type of response in the posttest. This occurred both in each phase of MPS (before, during, after), and in the final summary of the data, which is presented below.

To compare the statistical significance of the data, we proceeded to calculate Pearson's chi-square, which allowed us to evaluate the association between the pretest/posttest situation and the number of positive/negative responses. The obtained results are shown in Tables 3-5, indicating both the expected and the observed values (count).

The corresponding corrected typified residues are also included. These values, when they were greater than 1.96, indicated higher values than those that should appear in the condition of independence and similarly lower if their value was lower than -1.96 .

Table 3. Contingency table for cognitive level * pretest/posttest.

\begin{tabular}{|c|c|c|c|c|c|}
\hline & & & Pretest & Posttest & Total \\
\hline \multirow{6}{*}{ Cognitive level } & \multirow{3}{*}{ Positive Self-dialogues } & Count & 57 & 118 & 175 \\
\hline & & Expected frequency & 91.4 & 83.6 & 175.0 \\
\hline & & Corrected residues & -8.2 & 8.2 & \\
\hline & \multirow{3}{*}{ Negative self-dialogues } & Count & 96 & 22 & 118 \\
\hline & & Expected frequency & 61.6 & 56.4 & 118.0 \\
\hline & & Corrected residues & 8.2 & -8.2 & \\
\hline & \multirow{2}{*}{ Total } & Count & 153 & 140 & 293 \\
\hline & & Expected frequency & 153.0 & 140.0 & 293.0 \\
\hline
\end{tabular}

* The chi-square value was 67.225 with a sig value of 0.000 . 
Table 4. Contingency table for emotional level * pretest/posttest.

\begin{tabular}{|c|c|c|c|c|c|}
\hline & & & Pretest & Posttest & Total \\
\hline \multirow{6}{*}{ Emotional level } & \multirow{3}{*}{ Positive emotions } & Count & 42 & 87 & 129 \\
\hline & & Expected frequency & 66.9 & 62.1 & 129.0 \\
\hline & & Corrected residues & -5.8 & 5.8 & \\
\hline & \multirow{3}{*}{ Negative emotions } & Count & 114 & 58 & 172 \\
\hline & & Expected frequency & 89.1 & 82.9 & 172.0 \\
\hline & & Corrected residues & 5.8 & -5.8 & \\
\hline \multirow{2}{*}{\multicolumn{2}{|c|}{ Total }} & Count & 156 & 145 & 301 \\
\hline & & Expected frequency & 156.0 & 145.0 & 301.0 \\
\hline
\end{tabular}

* The Chi-square value is 35.573 with a Sig value: 0.000 .

Table 5. Table of contingency for motor level * pretest/posttest.

\begin{tabular}{|c|c|c|c|c|c|}
\hline & & & Pretest & Posttest & Total \\
\hline \multirow{6}{*}{ Motor level } & \multirow{3}{*}{ Positive performances } & Count & 87 & 105 & 192 \\
\hline & & Expected frequency & 108.6 & 83.4 & 192.0 \\
\hline & & Corrected residues & -6.8 & 6.8 & \\
\hline & \multirow{3}{*}{ Negative performances } & Count & 51 & 1 & 52 \\
\hline & & Expected frequency & 29.4 & 22.6 & 52.0 \\
\hline & & Corrected residues & 6.8 & -6.8 & \\
\hline & \multirow{2}{*}{ Total } & Count & 138 & 106 & 244 \\
\hline & & Expected frequency & 138.0 & 106.0 & 244.0 \\
\hline
\end{tabular}

* The chi-square value was 46.365 with a sig value of 0.000 .

Regarding the cognitive aspects, the following results were obtained.

As for the number of positive self-dialogues ("I have to read it several times to understand it better" and "I think I should have more patience next time" in the pretest; "I trust that if I follow the steps I will be able to solve it" and "Even if I have it wrong, at least I tried" in the posttest), we observed that their number (57) was lower than expected in the pretest (corrected typified residues $=-8.2$ ), while they were higher $(118)$ in the posttest (corrected typified residues $=8.2$ ). The results were just the opposite (96 and 22) in the case of negative self-dialogues ("I will not be able to solve it" and "I have done the problem wrong, I have failed" in the pretest; "I feel a little uneasy because I don't know if I'm going to know how to do the problem" in the posttest).

An increase in confidence and an attitudinal improvement, which reduced dropouts and effects derived from learned helplessness, was seen in the positive self-dialogues.

Regarding the emotional level, the results were as follows.

As for the number of positive emotions ("I think it's an easy problem, so I feel relaxed" and "[I feel] well, satisfied, having reached the solution" in the pretest; "I feel calm and relaxed" and "I feel happy to have tried and satisfied" in the posttest) that were expressed by the students, there were 42 in the pretest, which was a lower value than expected (corrected typified residues $=-5.8$ ), while there were 87 , a higher value than expected in the posttest (corrected typified residues $=5.8$ ). The results were the opposite (114 and 58 in pretest and posttest, respectively) in the case of negative emotions ("[I feel] distressed and nervous" and "I feel overwhelmed, I leave the problem" in the pretest; "I feel insecure but I will try to solve the problem" and "I feel indecisive because I don't know if I have solved the problem well" in the posttest). 
We observed how negative emotions already brought about abandonment and blockages towards MPS and the positive ones lead to greater tranquility, relaxation, security and self-confidence and higher expectations of self-efficacy.

Finally, regarding the motor level, the results were as follows.

As for the number of positive performances ("I start to read carefully and organize the data" and "I reread the data and try to reflect it in formulas" in the pretest; "I will apply the steps of the MPS model" and "I designed some strategies and I will check if they are fine" in the posttest) that were shown by the students, there were 87 , which was a lower value than expected in the pretest (corrected typified residues $=-6.8$ ), while there were 105, a higher value than expected, in the posttest (corrected typified residues $=6.8$ ). The results (51 and 1, in pretest and posttest) were the opposite in the case of negative expressions ("If I don't find the solution or the way to solve [the problem] quickly, I think I don't know how to do it and I leave it unsolved" and "I try to copy and memorize to solve some similar problem" in the pretest).

Regarding the greater number of positive actions before the MPS in the pretest, it should be noted that these actions were limited to the rereading of the problem and the extraction of explicit data; during MPS, they tried to solve the problem but without looking for different resolution paths, focusing only on the application of formulas and algorithms, as well as rereading the problem statement. When they did not find a solution quickly, they immediately gave up. Those EPMs who acknowledged not persevering corresponded mostly to those that, both before and during the RPM, were blocked, left and/or expected the help of their peers, or they copied their solution. Thus, the few who reached the end of the problem due to the high percentage of premature abandonment either reviewed and re-reviewed the mathematical problem and proposed small improvement goals or copied and memorized the resolution of the problems once it was explained by the teacher. There were still cases at this point in the resolution that kept rereading. This showed the lack of applying the heuristics for the first phase of understanding/familiarisation with the problem statement.

However, in the posttest, they did not show negative attitudes of avoidance or abandonment, such as copying or waiting for the explanation, but the vast majority of PEPSTs tried to solve the problem through IMMPS, applying both relaxation and breathing techniques, self-instructions and different heuristics. The participants persisted in solving the problem, acting with greater rigour and attention during the process. After that, they continued to look for different resolution paths or checked or reviewed the resolution process and the result.

\section{Discussion and Conclusions}

The results found regarding the PEPSTs at the beginning of the programme in relation to anxiety towards MPS coincided with other studies [14,15,33-38] in terms of mathematical anxiety in general. It should be noted that the percentage of PEPSTs who presented high levels of anxiety was much higher in the present study. However, these results do not correspond to those carried out with university students, who presented an anxiety level that was lower than the intermediate value of the scale [39].

Students did not develop metacognitive processes, such as generalisation, regulation and process control regarding MPS. They simply reread the statement [11]. The results obtained corroborate what the PEPSTs showed in a previous study [21] in which learning heuristics was beneficial to be successful in MPS, as was the insistence towards mechanising the MPS process and in teaching methods. The emotional regulation and heuristic techniques presented demonstrated that by including them in the learning process and practising certain mathematical problem-solving methods, the students could learn ways of thinking about approaching and solving problems successfully [17].

Through the implementation of the programme, the PEPSTs achieved reflection, awareness, regulation and emotional autonomy. This resulted in an increase in emotional 
control, reduced negative emotions and levels of anxiety and improved security and self-confidence as problem solvers and expectations of success.

Similarly, blockages regarding MPS decreased and even disappeared, leading to the PEPSTs developing attitudes that were favourable to MPS such that they persevered in the search for different resolution strategies, including manipulative ones, among other positive attitudes.

On the other hand, the subjects under study dissociated themselves from the traditional conception of a mechanical MPS and the use of formulae, which resulted in the modification of their beliefs about MPS, together with the way it is taught and learnt.

Ultimately, we must indicate that there was a positive evolution relative to the initial self-perception of the PEPSTs as mathematical problems solvers and they showed a greater willingness to initiate changes in MPS.

We conclude that the relaxation and breathing techniques, self-instructions and a conscious reflection and modification of beliefs about MPS, originating from negative emotions, were facilitators of emotional regulation in this mathematical task. In addition, the IMMPS itself contributed to emotional regulation since it was not the resolution of problems in itself that led to the development of negative emotions but rather not knowing how to act when faced with this task. It showed that teaching a method for teaching problem solving in mathematics and teaching problem-solving strategies through mathematics can develop complex problem-solving skills [17].

The IMMPS had a positive effect on the development of MPS and fostered not only learning, emotional and cognitive regulation but also life skills [17].

In short, we believe that the programme achieved positive results, corroborating the importance and need to incorporate emotional skills in the profile of competencies to be developed in the training of future teachers.

Author Contributions: Conceptualisation: A.C.-C.; methodology, A.C.-C.; formal analysis, A.C.-C. and L.M.C.-G.; investigation, A.C.-C.; resources, A.C.-C.; data curation, A.C.-C.; writing-original draft preparation, A.C.-C., L.M.-N., L.M.C.-G. and L.M.S.-A.; writing-review and editing, A.C.-C.; visualisation, L.M.S.-A.; supervision, A.C.-C.; project administration, L.M.C.-G.; funding acquisition, L.M.C.-G. All authors have read and agreed to the published version of the manuscript.

Funding: This research was funded by the European Regional Development Fund and the Junta de Extremadura, Projects GR18115 and GR18004.

Institutional Review Board Statement: The study was conducted according to the guidelines of the Declaration of Helsinki, and approved by the Bioethics and Biosafety Committeeof Universidad de Extremadura (File No. 158/2021 approved in 2021).

Informed Consent Statement: Informed consent was obtained from all subjects involved in the study.

Data Availability Statement: Not applicable.

Conflicts of Interest: The authors declare no conflict of interest. The funders had no role in the design of the study; in the collection, analyses, or interpretation of data; in the writing of the manuscript; or in the decision to publish the results.

\section{References}

1. Cárdenas, J.A.; Blanco, L.J. La Resolución de Problemas de Matemáticas como contenido en el currículo de Primaria. In La Resolución de Problemas de Matemáticas en la Formación Inicial de Profesores de Primaria; Blanco, L.J., Cárdenas, J.A., Caballero, A., Eds.; Universiddad de Extremadura: Cáceres, Spain, 2015; pp. 23-38.

2. Arcavi, A.; Friedlander, A. Curriculum developers and problem solving: The case of Israeli elementary school projects. ZDM Math. Educ. 2007, 39, 355-364. [CrossRef]

3. Caballero, A.; Guerrero, E.; Blanco, L.J. Construcción y administración de un instrumento para la evaluación de los afectos hacia las matemáticas. Campo Abierto 2014, 33, 47-71.

4. Garofalo, J. Beliefs, responses and mathematics education: Observations from the back of the classroom. Sch. Sci. Math. 1989, 89, 451-455. [CrossRef]

5. Blanco, L.J. Concepciones y creencias sobre la resolución de problemas de estudiantes para profesores y nuevas propuestas curriculares. Quadrante 1997, 6, 45-65. 
6. Gil, N. Creencias, Actitudes y Emociones en el Aprendizaje Matemático. Memoria de Investigación Para la Obtención del DEA; Departamento de Psicología y Sociología de la Educación, Universidad de Extremadura: Badajoz, Spain, 2003.

7. Córcoles, A.C.; Valls, J. Debates virtuales y concepciones de estudiantes para profesores sobre resolución de problemas. ZETETIKÉ 2006, 14, 7-28.

8. Báez, A. El Autoconcepto Matemático y las Creencias del Alumnado: Su Relación con el Logro de Aprendizaje, un Estudio Exploratorio, Descriptivo e Interpretativo en la ESO. Ph.D. Thesis, Universidad de Oviedo, Facultad de Filosofía y Letras, Oviedo, Spain, 2007.

9. Harskamp, E.; Suhre, C. Schoenfeld's problem solving theory in a student controlled learning environment. Comput. Educ. 2007, 49, 822-839. [CrossRef]

10. Santos, M. La Resolución de Problemas Matemáticos: Avances y Perspectivas en la construcción de una agenda de investigación y práctica. Investig. Educ. Matemática 2008, 12, 157-187.

11. Sánchez-Barbero, B.; Chamoso, J.M.; Vicente, S.; Rosales, J. Analysis of Teacher-Student Interaction in the Joint Solving of Non-Routine Problems in Primary Education Classrooms. Sustainability 2020, 12, 428. [CrossRef]

12. Schoenfeld, A.H. Problem solving in the United States, 1970-2008: Research and theory, practice and politics. ZDM Int. J. Math. Educ. 2007, 39, 537-551. [CrossRef]

13. Pino, J.; Blanco, L.J. Análisis de los problemas de los libros de texto de Matemáticas para alumnos de 12 a 14 años de edad de España y de Chile en relación con los contenidos de proporcionalidad. Publicaciones 2008, 38, 63-88.

14. Nortes, R.; Nortes, A. Ansiedad, motivación y confianza hacia las Matemáticas en futuros maestros de Primaria. Números 2017, 95, 77-92.

15. Segarra, Y.R.; Pérez-Tyteca, P. Nivel de ansiedad hacia las Matemáticas de futuros maestros de Educación Primaria. In Investigación en Docencia Universitaria. Diseñando el Futuro a Partir de la Innovación Educative; Roig-Vila, R., Ed.; Octaedro: Barcelona, Spain, 2017; pp. 442-451.

16. Hill, F.; Mammarella, I.C.; Devine, A.; Caviola, S.; Passolunghi, M.C.; Szucs, D. Maths anxiety in primary and secondary school students: Gender differences, developmental changes and anxiety specificity. Learn. Individ. Differ. 2016, 48, 45-53. [CrossRef]

17. Szabo, Z.K.; Körtesi, P.; Guncaga, J.; Szabo, D.; Neag, R. Examples of Problem-Solving Strategies in Mathematics Education Supporting the Sustainability of 21st-Century Skills. Sustainability 2020, 12, 10113. [CrossRef]

18. Palacios, A.; Arias, V.; Arias, B. Las actitudes hacia las matemáticas: Construcción y validación de un instrumento para su medida. Rev. Psicodidáctica 2014, 19, 67-91. [CrossRef]

19. Coelho, V.; Sousa, V.; Figueira, A.P. The impact of a school-based social and emotional learning program on the self-concept of middle school students. Rev. Psicodidáct. 2014, 19, 347-365. [CrossRef]

20. Bisquerra, R.; Pérez, N. Las competencias emocionales. Educ. XXI 2007, 10, 61-82. [CrossRef]

21. Giné, C.; Deulofeu, J. Conocimientos y Creencias en torno a la Resolución de Problemas de Profesores y Estudiantes de Profesor de Matemáticas. Bolem Bol. Educ. Matemát. 2014, 28, 191-208.

22. Hoffman, B.; Spatariu, A. The influence of self-efficacy and metacognitive prompting on math problem-solving efficiency. Contemp . Educ. Psychol. 2008, 33, 875-893. [CrossRef]

23. Martínez, M.; Valiente, C. Affective and motivational self-regulation, resolution of problems and performance in the area of mathematics in Primary Education. Educ. Siglo XXI 2019, 37, 33-54.

24. Carpenter, T.; Fennema, E. Cognitively guided instruction: Building on the knowledge of students and teachers. Int. J. Res. Educ. 1992, 17, 457-470. [CrossRef]

25. Palomera, R.; Fernández-Berrocal, P.; Brackett, M. La inteligencia emocional como una competencia necesaria en la formación inicial del profesorado: Algunas evidencias. In Psicología y Educación: Un Lugar de Encuentro, Proceedings of the $V$ Congreso Internacional de Psicología y Educación: Los Retos del Future, Oviedo, España, 23-25 April 2008; González-Pienda, J.A., Núñez, J.C., Eds.; Ediciones de la Universidad de Oviedo: Oviedo, Spain, 2008; p. 135.

26. Polya, G. Cómo Plantear y Resolver Problemas; Trillas: México, Mexico, 1985.

27. Schoenfeld, A.H. Mathematical Problem Solving; Academic Press: New York, NY, USA, 1985.

28. Mayer, J.D.; Salovey, P. Emotional Development and Emotional Intelligence: Implications for Educators; Basic Books: New York, NY, USA, 1997.

29. Gross, J.J. The future's so bright, I gotta wear shades. Emot. Rev. 2010, 2, 212-216. [CrossRef]

30. Jacobson, E. Relajación Progresiva; Prensa de la Universidad de Chicago: Chicago, CA, USA, 1938.

31. Meichenbaum, D. Manual de Inoculación de Estrés; Martínez Roca: Barcelona, Spain, 1987.

32. Spielberger, C.D.; Gorsuch, R.R.; Lushene, R.E. STAI. Cuestionario de Ansiedad Estado/Rasgo; TEA Ediciones: Madrid, Spain, 1982.

33. Sánchez, J.; Segovia, I.; Miñán, A. Exploración de la ansiedad hacia las matemáticas en los futuros maestros de Educación Primaria. Profesorado. Rev. Currículum Form. Profr. 2011, 15, 297-312.

34. Bekdemir, M. The pre-service teachers' mathematics anxiety relate to deth of negative experiences in mathematics classroom whil they were students. Educ. Stud. Math. 2010, 75, 311-328. [CrossRef]

35. Bursal, M.; Paznokas, L. Mathematics anxiety and pre-service elementary teachers' confidence to teach mathematics and science. Sch. Sci. Math. 2006, 106, 173-179. [CrossRef]

36. Hembree, R. The nature, effects, and relief of mathematics anxiety. J. Res. Math. Educ. 1990, 21, 33-46. [CrossRef]

37. Jackson, E. Mathematics anxiety in student teachers. Pract. Res. High. Educ. 2008, 2, 36-42. 
38. Rayner, V.; Pitsolantis, N.; Osana, H. Mathematics anxiety in preservice teachers: Its relationship to their conceptual and procedural knowledge of fractions. Math. Educ. Res. J. 2009, 21, 60-85. [CrossRef]

39. Pérez-Tyteca, P.; Castro, E.; Rico, L.; Castro, E. Ansiedad matemática, género y ramas de conocimiento en alumnos universitarios. Enseñ. Cienc. 2011, 29, 237-250. 